\title{
ANTICHOLINERGIC PREMEDICATION
}

\author{
Kenneth M. Leighton and Harvey D. Sanders
}

ONE OF THE TRADITIONAL REASONS for the preanaesthetic administration of anticholinergic agents has been to reduce oropharyngeal and tracheobronchial secretions. When irritating inhalational anaesthetics were employed, this drying effect was a necessary preliminary to the induction of anaesthesia. The practice of administering anticholinergics before general anaesthesia has persisted in spite of the non-irritant nature of modern anaesthetics.

A number of studies have been carried out to investigate the necessity for premedication with these drugs. One of these demonstrated that general anaesthesia may be carried out efficiently and safely without the muscarinic blockade produced by atropine, scopolamine or other agents. ${ }^{1}$ A more recent clinical report, however, indicates that these drugs are of benefit and that their omission is not advisable unless their employment is specifically contraindicated. ${ }^{2}$

The authors of the latter report acknowledge the distress which anticholinergic medication may cause the patient and also the potentially harmful effects of these drugs. Unfortunately, the authors did not indicate their criteria for "satisfactory premedication," nor in what respect their patients were "unsatisfactory" when they had not received anticholinergic premedication.

The present authors determined to ask a group of anaesthetists in a large teaching hospital what differences they observed (as far as mouth and respiratory tract secretions were concerned) between patients who received anticholinergic premedication and those who did not.

The following questions were asked:

1. If anticholinergic premedication was omitted, did secretions constitute a problem during or after the anaesthetic?

2. If there was a problem, what was its nature?

3. Was an anticholinergic then administered? If so, with what result?

\section{Methods and Materials}

Eleven anaesthetists participated in the study for one year. When anticholinergic drugs were used, either atropine or scopolamine was administered approximately one hour before anaesthesia. No attempt was made at formal randomization; that is to say, the participating anaesthetist was at liberty to use an anticholinergic agent in premedication in any given patient. Not all patients anaesthetized by each anaesthetist were included in the study, but none was rejected or omitted for any reason other than that protocol forms were not available, or some other pressure of circumstances precluded the charting of relevant data.

Kenneth M. Leighton, M.B., F.R.C.P.(C), and Harvey D. Sanders, M.D., Ph.D., Departments of Anaesthesia and Pharmacology, Faculty of Medicine, The University of British Columbia, Vancouver, B.C., Canada. V6T 1W5. 
Most of the anaesthetists who participated in the study had a pre-existing bias in favour of anticholinergic premedication. All participated willingly in the study. No patients were placed at risk, in the opinion of the anaesthetist, by either the administration or the omission of anticholinergic medication.

The study group contained 404 patients. All general surgical cases were included. Open heart cases were not considered since, in this hospital, anticholinergic premedication is seldom employed for such patients. Both male and female patients were studied. No infants were included because it is the practice in this institution to administer anticholinergic premedication to all infants and young children.

Two hundred and forty-four patients (Group A) received no anticholinergic premedication.

One hundred and sixty patients (Group B) received either atropine or scopolamine $(0.6 \mathrm{mg}$ and $0.4 \mathrm{mg}$ respectively) by the intramuscular route one hour before anaesthesia.

Tracheal intubation was performed in 56 per cent of the patients who received anticholinergics and in 85 per cent of those who did not.

\section{RESULTS}

The results of the study are presented in Table 1.

Thirty-two patients ( 13 per cent) in Group A (no anticholinergic premedication) were reported to have had "problem secretions." Five of these 32 patients (i.e., 2 per cent) were given atropine for the management of these secretions with success.

Thus, two per cent of these unatropinised patients suffered troublesome secretions.

Six patients ( 3.75 per cent) in Group B were reported to have problem secretions, in spite of premedication with either atropine or scopolamine. None was given supplemental atropine.

Of the five patients in Group A who were considered to present a sufficient problem to warrant the administration of atropine, all had undergone tracheal intubation.

\section{TABLE I}

Patients who did not Receive Atropine or Scopolamine (Group A) CoMpared With those Where These Drugs were Administered in the Pre-Anaesthetic Period (Group B)

The number of patients with secretions which were sufficiently troublesome to require atropine during anaesthesia is indicated

\begin{tabular}{lcc}
\hline \hline & $\mathrm{A}$ & $\mathrm{B}$ \\
\hline $\begin{array}{l}\text { Number of patients } \\
\text { Number with "troublesome } \\
\text { secretions" "troublesome }\end{array}$ & 244 & 160 \\
$\begin{array}{l}\text { Number with" "troubletions" receiving } \\
\text { secretion } \\
\text { atropine as treatment }\end{array}$ & $5(2 \%)$ & $6(3.75 \%)$ \\
\hline
\end{tabular}




\section{Discussion}

The fundamental question of what constitutes "troublesome secretions," defies definition. It is apparent that this is a subjective evaluation on the part of the individual anaesthetist. It is difficult to devise a measurable endpoint.

The present investigators, therefore, decided to consider that secretions constituted a definite problem if the anaesthetist was constrained to administer an anticholinergic drug for their control. Anaesthetists were asked to describe any problems which they encountered whether or not they administered an anticholinergic agent before or during anaesthesia.

Excessive mouth or respiratory tract secretions might present the anaesthetist with problems in the conduct of anaesthesia. The most serious problem which excessive secretions might present to the anaesthetist would presumably be airway obstruction. Such obstruction might threaten the ventilation of the patient. Airway obstruction might also impede the delivery of an inhalational anaesthetic. Another difficulty which an excessive amount of upper respiratory and oropharyngeal secretions might cause is the invasion of a sterile field about the head and neck. Excessive secretions may also be aesthetically unpleasant.

The only truly "troublesome" secretions, however, are those which present a threat to the patient's well-being or hinder the efficient conduct of the anaesthetic.

These latter criteria are difficult to assess from a study of anaesthetic records and even from specifically designed questionnaires.

However, taking a group of anaesthetists who favoured the use of anticholinergic premedication, it is a significant finding that in only 2 per cent of 244 anaesthetics where there had been no anticholinergic premedication were secretions considered to be such a problem that the anaesthetist was constrained to administer atropine. The fact that no additional anticholinergic was administered to those atropinized patients who nevertheless demonstrated "problem secretions" possibly reflects the stoicism with which anaesthetists accept such troublesome secretions in the patient who has received anticholinergic premedication.

In patients who have not received anticholinergic premedication secretions are not viscid and are more easily removed by suction than is the case after administration of anticholinergic.

The efficiency of ciliary motion is inhibited by excessively viscid tracheobronchial secretion. Ciliary efficiency is inhibited by anticholinergic medication. ${ }^{3,4}$ This not only prevents the scavenging activity of cilia, but also makes the mechanical removal of secretions more difficult because of their increased viscosity.

It seems irrational, therefore, to premedicate patients with anticholinergics, if the reason for the administration of these drugs is the drying of secretions, when only a small percentage of patients requires more than mechanical suction. Such patients can be treated at the time of need.

Oropharyngeal airways, tracheal intubation and laryngotracheal surgical procedures predispose to increased secretions from the mouth and respiratory tract. The greater the stimulus, the more the secretion. Thus, in an intubated patient, an oropharyngeal airway which is probably necessary only when the tracheal tube is removed may make the mouth unnecessarily moist during the anaesthetic: This is particularly likely to occur if there is any movement of the airway as a result of 
surgical and other manipulation. It seems unnecessary to use such an airway when the muscles are paralysed. It is not likely that the patient will occlude the tracheal tube by biting it.

Oropharyngeal airways are often necessary, of course, during spontaneous respiration through a face mask.

From this clinical study we conclude that an incidence of 2 per cent of comparatively minor secretory problems does not warrant the routine administration of anticholinergic drugs before general anaesthesia, when the sole rationale for the administration of these agents is the drying of the mouth and tracheobronchial tree.

\section{SUMMARY}

Two hundred and forty-four surgical patients who received no anticholinergic premedication were compared with 160 patients who had received atropine or scopolamine before the induction of anaesthesia. Infants and patients undergoing heart surgery were excluded. Eleven anaesthetists participated in the study. They were asked to report problems with oropharyngeal and tracheobronchial secretions. Two per cent of unpremedicated patients experienced problems with secretions of a degree sufficient to require treatment. This small percentage appears insufficient to warrant routine preoperative anticholinergic medication.

\section{RÉSUiMé}

Nous avons comparé 244 patients n'ayant pas reçu d'agent anticholinergique dans leur prémédication avec 160 opérés dont la prémédication comprenait de l'atropine ou de la scopolamine. Etaient exclus de cette étude les bébés et les malades soumis à une chirurgie cardiaque.

Nous avions demandé aux onze anesthésistes participant à l'étude de rapporter tout problème lié à la présence de sécrétions orpharyngées ou trachéobronchiques.

Deux pour cent seulement des patients n'ayant pas reçu de prémédication ont présenté suffisamment de sécrétions pour en justifier un traitement. Ce bas pourcentage nous semble insuffisant pour justifier l'usage routinier d'agent anticholinergique dans la prémédication.

\section{ACKNOWLEDGEMENT}

The authors wish to thank their colleagues in the Department of Anaesthesia, Vancouver General Hospital who participated in this study.

\section{REFERENCES}

1. Levy, M.L., Ponter, V.P, \& Conkley, C.C. Premedication without vagal blocking drugs. Anesth. Analg. 43, 1:33 (1964).

2. Fabick, Y.S. \& SMILEn, B.G. Is anticholinergic premedication necessary? Anesthesiology 43, 4: 472 (1975).

3. InNES, I.R. \& Nickerson, A. Atropine, scopolamine and related antimuscarinic drugs. In The Pharmacological Basis of Therapeutics, Louis S. Goodman and Alfred Gilman (eds.), 5th edition, p. 518 ( 1975 ).

4. ANNIS, P., LANDA, J., \& Lichtiger, M. Effects of atropine on velocity of tracheal mucus in anaesthetized patients. Anesthesiology 44, 1: 74 (1976). 